\title{
Article
}

\section{Global Deletion of 11ß-HSD1 Prevents Muscle Wasting Associated with Glucocorticoid Therapy in Polyarthritis}

\author{
Justine M. Webster ${ }^{1,2, *, \dagger}$, Michael S. Sagmeister ${ }^{1,+}+{ }^{-}$, Chloe G. Fenton ${ }^{1,3}$, Alex P. Seabright ${ }^{4}$, Yu-Chiang Lai ${ }^{4}$, \\ Simon W. Jones ${ }^{5}{ }^{(D}$, Andrew Filer ${ }^{3,5}$, Mark S. Cooper ${ }^{6}$, Gareth G. Lavery ${ }^{1,5}$, Karim Raza ${ }^{3,5,7}{ }^{1}$, Ramon Langen ${ }^{2,+}$ \\ and Rowan S. Hardy $1,3,8,+[1$
}

Citation: Webster, J.M.; Sagmeister, M.S.; Fenton, C.G.; Seabright, A.P.; Lai, Y.-C.; Jones, S.W.; Filer, A.; Cooper, M.S.; Lavery, G.G.; Raza, K.; et al. Global Deletion of $11 \beta-$ HSD1 Prevents Muscle Wasting Associated with Glucocorticoid Therapy in Polyarthritis. Int. J. Mol. Sci. 2021, 22, 7828. https://doi.org/ 10.3390/ijms22157828

Academic Editor: Elizabeth W. Bradley

Received: 18 May 2021

Accepted: 16 July 2021

Published: 22 July 2021

Publisher's Note: MDPI stays neutral with regard to jurisdictional claims in published maps and institutional affiliations.

Copyright: (c) 2021 by the authors. Licensee MDPI, Basel, Switzerland. This article is an open access article distributed under the terms and conditions of the Creative Commons Attribution (CC BY) license (https:// creativecommons.org/licenses/by/ $4.0 /)$.
1 Institute for Metabolism and Systems Research, College of Medical and Dental Sciences, University of Birmingham, Birmingham B15 2TT, UK; M.Sagmeister@bham.ac.uk (M.S.S.); chloe.fenton@uni-wuerzburg.de (C.G.F.); G.G.Lavery@bham.ac.uk (G.G.L.); r.hardy@bham.ac.uk (R.S.H.)

2 Department of Respiratory Medicine, NUTRIM School of Nutrition and Translational Research in Metabolism, Faculty of Health, Medicine and Life Sciences, Maastricht University, 6211 LK Maastricht, The Netherlands; r.langen@maastrichtuniversity.nl

3 Research into Inflammatory Arthritis Centre Versus Arthritis, Institute of Inflammation and Ageing, University of Birmingham, Birmingham B15 2TT, UK; A.FILER@bham.ac.uk (A.F.);

K.Raza@bham.ac.uk (K.R.)

4 School of Sport, Exercise and Rehabilitation Sciences, University of Birmingham, Birmingham B15 2TT, UK; AXS564@student.bham.ac.uk (A.P.S.); Y.Lai.1@bham.ac.uk (Y.-C.L.)

5 MRC Arthritis Research UK Centre for Musculoskeletal Ageing Research, University of Birmingham, Birmingham B15 2TT, UK; S.W.Jones@bham.ac.uk

6 ANZAC Research Institute, The University of Sydney, Sydney, NSW 2139, Australia; mark.cooper@sydney.edu.au

7 Department of Rheumatology, Sandwell and West Birmingham NHS Trust, Birmingham B71 4HJ, UK

8 Institute of Clinical Science, University of Birmingham, Birmingham B15 2TT, UK

* Correspondence: JMW801@student.bham.ac.uk

+ These authors contributed equally.

Abstract: Glucocorticoids provide indispensable anti-inflammatory therapies. However, metabolic adverse effects including muscle wasting restrict their use. The enzyme 11beta-hydroxysteroid dehydrogenase type 1 (11ß-HSD1) modulates peripheral glucocorticoid responses through prereceptor metabolism. This study investigates how $11 \beta$-HSD1 influences skeletal muscle responses to glucocorticoid therapy for chronic inflammation. We assessed human skeletal muscle biopsies from patients with rheumatoid arthritis and osteoarthritis for 11 $\beta$-HSD1 activity ex vivo. Using the TNF- $\alpha-$ transgenic mouse model (TNF-tg) of chronic inflammation, we examined the effects of corticosterone treatment and $11 \beta$-HSD1 global knock-out $(11 \beta \mathrm{KO})$ on skeletal muscle, measuring anti-inflammatory gene expression, muscle weights, fiber size distribution, and catabolic pathways. Muscle 11 $\beta$-HSD1 activity was elevated in patients with rheumatoid arthritis and correlated with inflammation markers. In murine skeletal muscle, glucocorticoid administration suppressed IL6 expression in TNF-tg mice but not in TNF-tg ${ }^{11 \beta K O}$ mice. TNF-tg mice exhibited reductions in muscle weight and fiber size with glucocorticoid therapy. In contrast, TNF- $\operatorname{tg}^{11 \beta K O}$ mice were protected against glucocorticoid-induced muscle atrophy. Glucocorticoid-mediated activation of catabolic mediators (FoxO1, Trim63) was also diminished in TNF-tg ${ }^{11 \beta K O}$ compared to TNF-tg mice. In summary, 11ß-HSD1 knock-out prevents muscle atrophy associated with glucocorticoid therapy in a model of chronic inflammation. Targeting $11 \beta$-HSD1 may offer a strategy to refine the safety of glucocorticoids.

Keywords: sarcopenia; myopathy; steroids; adverse effects; 11 beta hydroxysteroid dehydrogenase type 1; rheumatoid arthritis; inflammation

\section{Introduction}

Glucocorticoids are indispensable in modern medicine as highly effective anti-inflamm atory medications. They are widely used with applications ranging from autoimmune 
diseases to cancer, organ transplantation, or COVID-19 pneumonia. Their capacity to control inflammation relies on direct action on immune cells [1,2]. However, action on tissues besides the immune system leads to a characteristic pattern of adverse effects that restricts their long-term use [2,3]. In skeletal muscle, glucocorticoids cause weakness and atrophy through pathways including reduced anabolic insulin-like growth factor 1 (IGF1)/insulin signaling and enhanced catabolic signaling via the ubiquitin-proteosome system [4]. Patients suffer detrimental consequences from muscle wasting in the form of reduced mobility, higher falls and fracture risk, higher hospitalization rates and increased mortality [5].

The enzyme 11beta-hydroxysteroid dehydrogenase type 1 (11 $\beta$-HSD1) modulates the signal strength of glucocorticoids within target tissues, including in skeletal muscle [6]. It converts inactive glucocorticoids (cortisone or prednisone in humans; dehydrocorticosterone (DHC) in rodents) to active glucocorticoids (cortisol/prednisolone/corticosterone), amplifying the local glucocorticoid signal. 11ß-HSD1 has been implicated in a range of metabolic pathologies [6]. In particular, suppression of 11 $\beta$-HSD1 protects against muscle wasting from glucocorticoid excess, highlighting $11 \beta-H S D 1$ as a potential target for therapeutic intervention $[7,8]$. Pharmaceutical inhibitors of $11 \beta-H S D 1$ have been developed and are in clinical trials for diabetes and other metabolic diseases [9-11].

Inflammation enhances the activity of $11 \beta$-HSD1. Inflammatory cytokines such as TNF- $\alpha$ upregulate $11 \beta-H S D 1$ expression, providing a local negative feedback to control inflammation with local anti-inflammatory glucocorticoid activation [12,13]. Inflammation also acts systemically to augment circulating glucocorticoids (activation of the hypothalamic-pituitary-adrenal (HPA) axis), as well as acting directly on skeletal muscle to cause myopathy [14]. Hence, compound effects on skeletal muscle depend on complex interactions between inflammation, 11 $\beta$-HSD1 activity and glucocorticoid signaling.

Our previous work showed that both the genetic deletion of 11 $\beta$-HSD1 and exogenous glucocorticoid, administered at a dose sufficient to suppress disease activity, exacerbate the muscle wasting phenotype in a model of polyarthritis with chronic inflammation [13,15]. This study addresses whether suppression of 11 $\beta$-HSD1 function will protect or harm skeletal muscle metabolism when chronic inflammation and exogenous glucocorticoids are combined in a murine model of glucocorticoid-treated polyarthritis. Our data show

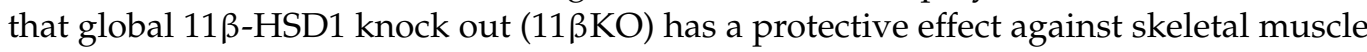
wasting when mice with chronic TNF- $\alpha$ overexpression receive oral corticosterone. This offers new insights into the driving factors for muscle wasting in glucocorticoid-treated inflammatory disease, with implications for strategies to mitigate the adverse effects of glucocorticoid treatments in the future.

\section{Results}

2.1. Cortisol Activation by 11ß-HSD1 Is Increased in Skeletal Muscle in Rheumatoid Arthritis and Correlates with Inflammation

Inflammatory upregulation of $11 \beta-H S D 1$ has previously been demonstrated when skeletal muscle samples from patients with osteoarthritis (OA) were stimulated with TNF- $\alpha$ ex vivo [13]. Here, we investigated whether inflammatory upregulation of $11 \beta-H S D 1$ is evident in muscle biopsies from patients with rheumatoid arthritis (RA), a condition with chronic systemic inflammation. Patients with OA and RA had similar age, but systemic inflammation markers were higher in patients with RA including C-reactive protein (CRP) and erythrocyte sediment rate (ESR) (Table 1). Exclusion criteria stipulated that no patient received current oral glucocorticoid therapy. Measuring ex vivo cortisone to cortisol conversion rate, we confirmed that $11 \beta$-HSD1 enzymatic activity was higher in muscle biopsies taken from patients with RA compared to patients with OA (mean \pm std. error: $0.014 \pm 0.001 \mathrm{pmol} / \mathrm{mg}$ tissue $/ \mathrm{h}$ vs. $0.010 \pm 0.001 \mathrm{pmol} / \mathrm{mg}$ tissue $/ \mathrm{h}$ respectively, $p<0.05$; Figure 1A). Among patients with RA, muscle $11 \beta$-HSD1 activity correlated with circulating CRP levels $\left(R^{2}=0.131, p=0.05\right.$; Figure $\left.1 B\right)$. Real-time PCR showed higher expression of the inflammatory cytokine IL6 in muscle samples from patients with RA compared to patients with OA (fold change $=8.65, p<0.05$; Figure 1C). Expression of this tissue-specific marker of inflammation correlated with expression of $11 \beta$-HSD1 among patients with 
RA $\left(R^{2}=0.369, p<0.05\right.$; Figure 1D). Similarly, expression of the inducible inflammatory activator COX2 correlated with 11 $\beta$-HSD1 expression in muscle biopsies from patients with RA $\left(R^{2}=0.672, p<0.05\right.$; Figure 1E). Finally, muscle samples from patients with RA compared to OA exhibited higher expression of Forkhead box protein O1 (FOXO1) and myostatin $(M S T N)$, negative regulators of muscle growth (fold changes 2.35, $p<0.05$ and 3.62, $p<0.05$ respectively; Figure 1F,G). Taken together, these data demonstrate that $11 \beta$-HSD1 activity is elevated in the skeletal muscle of patients with RA relative to patients with OA, and that $11 \beta-H S D 1$ upregulation correlates with systemic and tissue-specific markers of inflammation.

Table 1. Patients' characteristics for human skeletal muscle biopsies.

\begin{tabular}{cccc}
\hline Patient Details & $\begin{array}{c}\text { Patients with OA } \\
(\mathbf{n}=\mathbf{1 2})\end{array}$ & $\begin{array}{c}\text { Patients with RA } \\
(\mathbf{n}=\mathbf{1 0})\end{array}$ & $\begin{array}{c}\text { Group Comparison } \\
(\boldsymbol{p} \text {-Value })\end{array}$ \\
\hline Age (years) & $66.2+3.3$ & $65.7+4.1$ & 0.93 \\
\hline CRP $(\mathrm{mg} / \mathrm{L})$ & $2.3+1.7$ & $11.0+3.5$ & 0.03 \\
\hline ESR $(\mathrm{mm} / \mathrm{h})$ & $1.9+1.0$ & $24.13+7.1$ & 0.001 \\
\hline Methotrexate $(\mathrm{n})$ & 0 & 5 & na \\
\hline Anti-TNF therapy $(\mathrm{n})$ & 0 & 2 & na \\
\hline Prednisolone & 0 & 0 & na
\end{tabular}

A

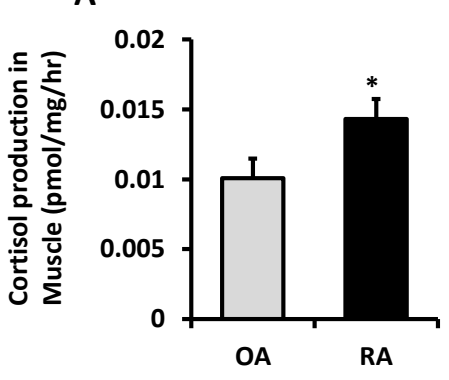

D

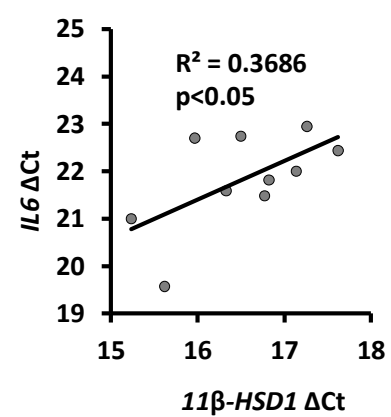

B

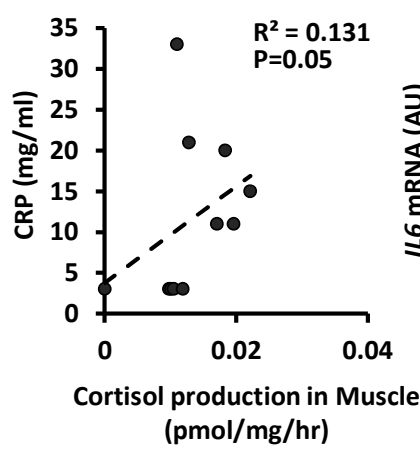

E

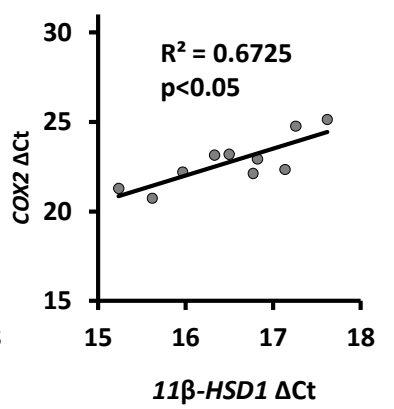

C

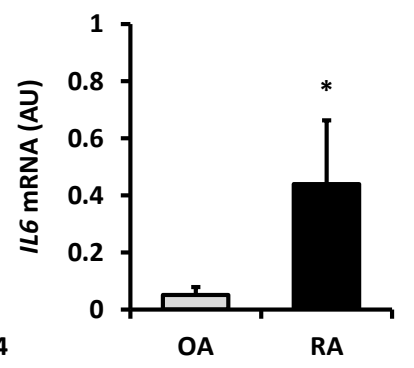

F

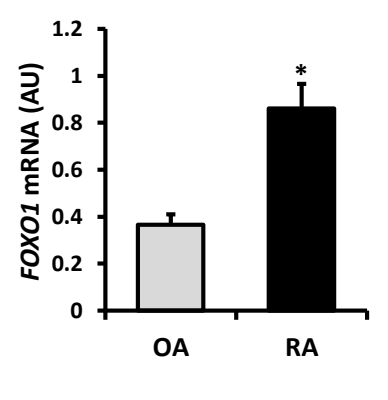

G

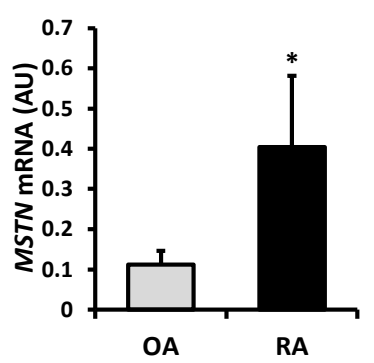

Figure 1. (A) Glucocorticoid activation by $11 \beta-H S D 1$ in ex vivo muscle explants freshly isolated after joint replacement surgery from patients with rheumatoid arthritis $(\mathrm{RA}, \mathrm{n}=10)$ and osteoarthritis $(\mathrm{OA} \mathrm{n}=12)$ determined by scanning thinlayer chromatography. (B) A significant correlation was seen between glucocorticoid activation (oxoreductase activity) and the serum C-reactive protein (CRP) measured before surgery in RA patients. (C) Gene expression (AU) of IL6 determined by RT qPCR in muscle homogenates from RA $(n=6)$ and OA $(n=4)$ patients. (D) Correlation between gene expression $(\triangle \mathrm{Ct})$ of 11ß-HSD1 with IL6 and (E) COX2 determined by RT qPCR in muscle homogenates from RA $(\mathrm{n}=6)$ and OA $(\mathrm{n}=4)$ patients. (F) Gene expression (AU) of FOXO1 and (G) MSTN determined by RT qPCR in muscle homogenates from RA $(n=5)$ and OA $(n=4)$ patients. Values are expressed as mean \pm standard error. Statistical significance was determined using an unpaired $t$-test. ${ }^{*} p<0.05$. 


\subsection{Deletion of $11 \beta-H S D 1$ in a Model of Chronic Inflammation Causes Resistance to the Anti-Inflammatory Responses of Therapeutic Glucocorticoid in Muscle}

$11 \beta$-HSD1 function has emerged as essential for glucocorticoid therapy to suppress joint inflammation in models of polyarthritis [16]. We therefore investigated how deletion of $11 \beta$-HSD1 affects anti-inflammatory responses in muscles when mice with inflammation from transgenic human TNF- $\alpha$ overexpression are treated with oral corticosterone. The skeletal muscle tissue from $11 \beta \mathrm{KO}$ mice exhibited no detectable activity to activate DHC to corticosterone (Figure 2A). Systemic treatment with corticosterone led to a $50 \%$ adrenal weight reduction in TNF-tg mice relative to untreated controls ( $p<0.05$; Figure 2B). For TNF-tg $11 \beta K O$ mice, adrenal weight reduction with corticosterone treatment was $60 \%$ relative to untreated counterparts $(p<0.05$; Figure 2B). Oral corticosterone treatment in TNF-tg mice led to a trend for higher muscle mRNA expression of Gilz, a glucocorticoid responsive gene with anti-inflammatory properties (Figure 2C). However, such a trend for corticosterone-induced Gilz expression was not apparent in TNF-tg $11 \beta \mathrm{KO}$ mice. In direct comparison of corticosteronetreated groups, muscle Gilz expression was significantly higher in TNF-tg mice than in TNF$\operatorname{tg}^{11 \beta K O}$ mice (fold change $=2.98, p<0.05$ ). Examination of $I l 6$ mRNA expression in muscle yielded consistent results. While corticosterone administration suppressed expression of proinflammatory Il6 in TNF-tg mice (fold change $=0.27, p<0.05$; Figure 2D), corticosterone was rendered ineffective in TNF-tg ${ }^{11} \beta K O$ mice (fold change $=0.96, p$-value NS). Primary muscle cultures of WT and $11 \beta \mathrm{KO}$ animals confirmed that $11 \beta \mathrm{KO}$ muscle cells are unresponsive to the inactive glucocorticoid DHC and its immunosuppressive effects. DHC does not activate the glucocorticoid receptor directly but relies on conversion to active corticosterone by $11 \beta$ HSD1 to trigger glucocorticoid responses. Accordingly, DHC stimulation markedly enhances Gilz mRNA expression in WT muscle cells, but not in 11ßKO cells (Figure 2E,F). Similarly, DHC stimulation markedly suppresses TNF-induced $I l 6$ mRNA expression in WT muscle cells, but not in $11 \beta \mathrm{KO}$ cells (Figure $2 \mathrm{G}, \mathrm{H}$ ). Together, these data reveal that anti-inflammatory responses of glucocorticoids in skeletal muscle are dependent on 11ß-HSD1.
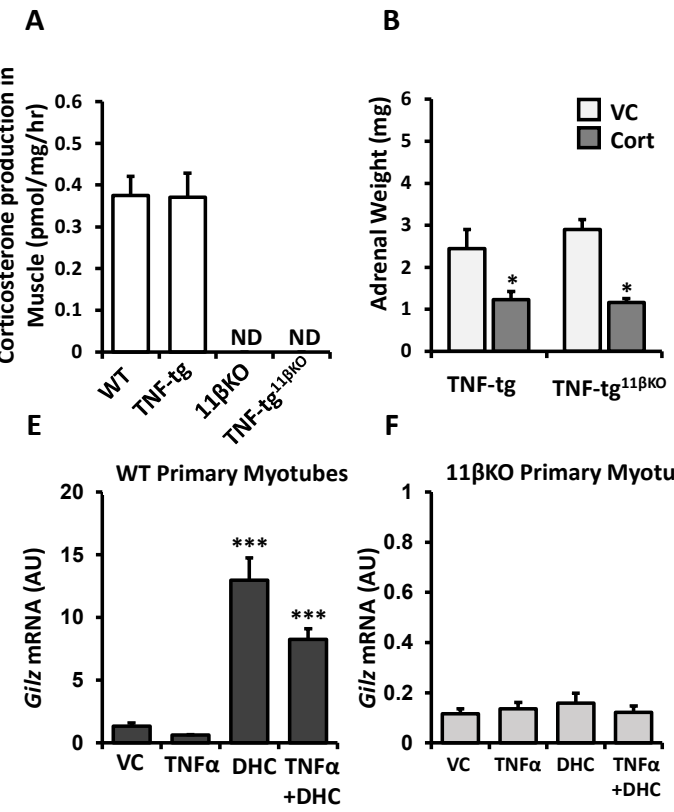

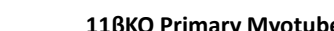

c
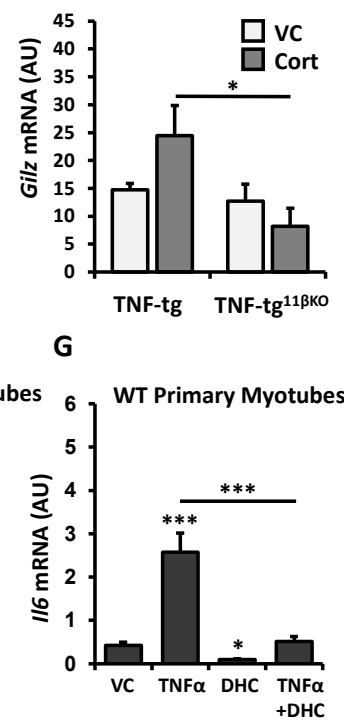

D

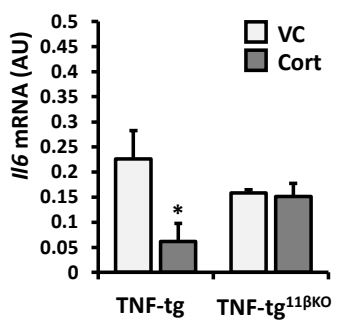

H

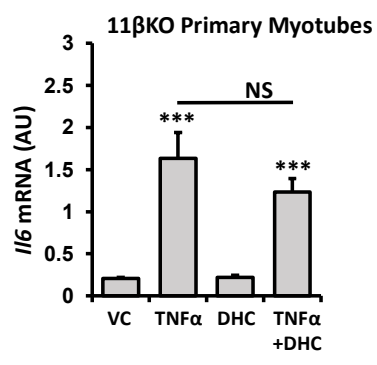

Figure 2. (A) Corticosterone production (pmol/mg/hour) determined by scanning thin layer chromatography in ex vivo tibialis anterior muscle biopsy isolated from wild type (WT), TNF-transgenic (TNF-tg), 11ß-HSD1 knock out (11ßKO) and TNF-tg ${ }^{11 \beta K O}$ animals. (B) Adrenal weights and gene expression (AU) of (C) Gilz and (D) Il6 determined by RT qPCR in muscle homogenates from TNF-tg and TNF-tg $11 \beta K O$ animals receiving either vehicle or corticosterone $(100 \mu \mathrm{g} / \mathrm{mL}) \mathrm{in}$ the drinking water for 3 weeks. Gene expression (AU) of (E,F) Gilz and $(\mathbf{G}, \mathbf{H})$ Il6 in primary murine muscle cultures from WT or single mutant $11 \beta \mathrm{KO}$ animals treated with recombinant TNF $\alpha$ and/or dehydrocorticosterone (DHC) determined by RT qPCR. Values are expressed as mean $\pm \mathrm{SE}, \mathrm{n}=6$ per group for animal experiments and $\mathrm{n}=3$ per group for primary culture. Statistical significance was determined using two-way analysis of variance with Tukey post hoc analysis. ${ }^{*} p<0.05,{ }^{* * *} p<0.001$. NS, not significant; WT, Wild type; $11 \beta \mathrm{KO}, 11 \beta-H S D 1$ genetic deletion; VC, Vehicle Control; Cort, Corticosterone; DHC, Dehydrocorticosterone; ND, not detectable. 


\subsection{1ß-HSD1 Mediates Muscle Wasting in Response to Therapeutic Glucocorticoids in Chronic Inflammation}

Global deletion of $11 \beta$-HSD1 has previously been shown to exacerbate myopathy in the inflammatory model of TNF-tg mice but protect against myopathy in the glucocorticoid excess model of WT mice receiving oral corticosterone $[13,15]$. Next, we explored the role of $11 \beta-H S D 1$ for muscle atrophy in a combined model of TNF-tg mice treated with corticosterone.

Tibialis anterior and quadriceps muscle weights (standardized to total body weights) were assessed in the four experimental groups of vehicle-treated TNF-tg mice, corticosteronetreated TNF-tg mice, vehicle-treated TNF-tg ${ }^{11 \beta K O}$ mice and corticosterone-treated TNF$\operatorname{tg}^{11 \beta K O}$ mice (Figure $\left.3 \mathrm{~A}, \mathrm{~B}\right)$. In TNF-tg mice, corticosterone treatment reduced standardized tibialis anterior and quadriceps muscle weights compared to vehicle control $(-33 \%, p<0.05$ and $-29 \%, p<0.05$ respectively). In TNF-tg $11 \beta K O$ mice however, corticosterone treatment had no significant effect on muscle weights relative to vehicle treatment (TA: $-4 \%, p$-value NS and quadriceps: $+12 \%$, $p$-value NS). In direct comparison of corticosterone-treated TNF-tg animals and corticosterone-treated TNF-tg $11 \beta \mathrm{KO}$ animals, standardized muscle weights were significantly greater in the latter group (TA: $+49 \%, p<0.05$ and quadriceps: $+43 \%, p<0.01)$.

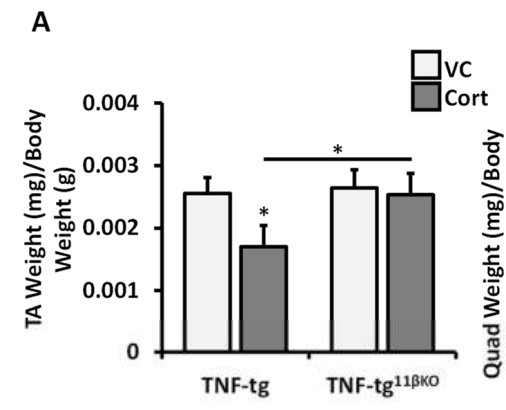

B

C
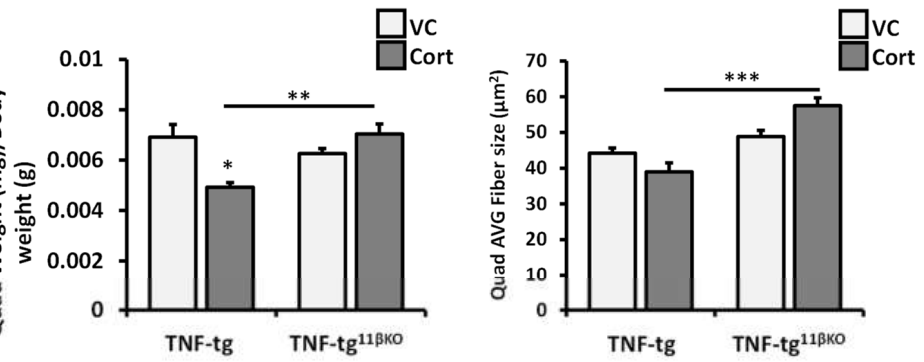

D
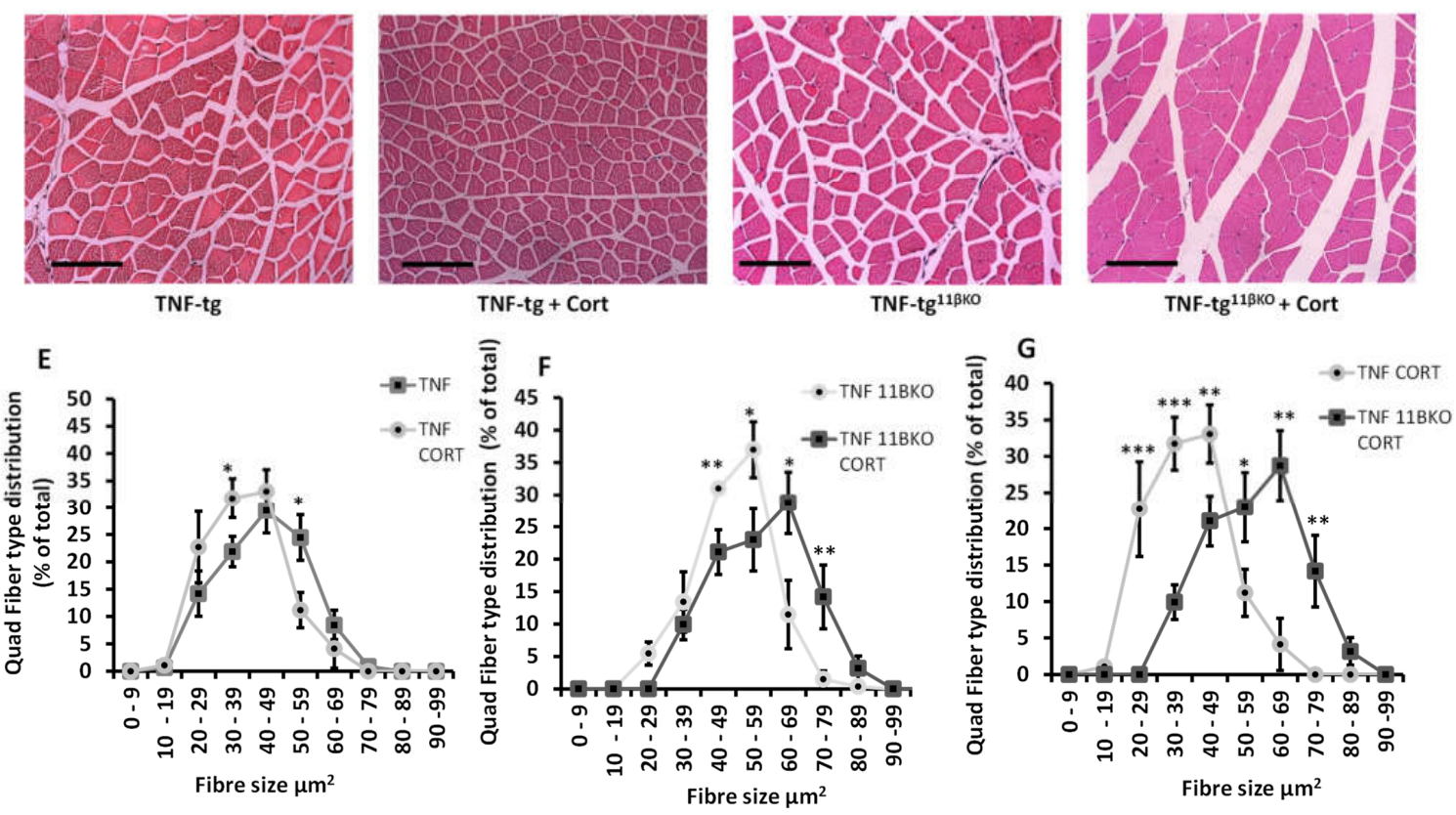

Figure 3. Total (A) Tibialis anterior (TA) and (B) quadriceps muscle weights relative to total bodyweight and (C) average quadriceps muscle fibre cross sectional area $\left(\mu \mathrm{m}^{2}\right)$ in TNF-tg, and TNF-tg ${ }^{11 \beta K O}$ animals receiving either vehicle or corticosterone $(100 \mu \mathrm{g} / \mathrm{mL})$ in the drinking water for 3 weeks. (D) Representative images of quadriceps muscle sections and (E-G) distribution of quadriceps muscle fibre cross-sectional area determined using Image J in paraffin embedded sections in TNF-tg, and TNF-tg ${ }^{11 \beta K O}$ animals receiving either vehicle or corticosterone $(100 \mu \mathrm{g} / \mathrm{mL})$ in the drinking water for three weeks. Values are expressed as mean \pm standard error of six animals per group. Statistical significance was determined using two-way ANOVA with a Tukey post hoc analysis. ${ }^{*} p<0.05,{ }^{* *} p<0.005,{ }^{* * *} p<0.001$ (scale bars, $50 \mu \mathrm{m}$ ). VC $=$ Vehicle Control, Cort $=$ Corticosterone. 
Quantitative analysis of average muscle fiber size and distribution yielded matching results. The average fiber cross-sectional area was significantly larger in corticosteronetreated TNF-tg ${ }^{11 \beta K O}$ mice than in treated TNF-tg mice $\left(57.5 \mu \mathrm{m}^{2}\right.$ vs. $39.0 \mu \mathrm{m}^{2}, p<0.001$; Figure $3 \mathrm{C}$ and Supplementary Figure S2). Examined in closer detail, corticosterone treatment for TNF-tg mice produced a left shift in fiber size distribution (i.e., higher frequency of small fibers and lower frequency of large fibers (Figure 3E)). In contrast, corticosterone treatment for TNF-tg $11 \beta K O$ mice produced a right shift in fiber size distribution (Figure 3F). When muscle histology of corticosterone-treated TNF-tg and TNF-tg ${ }^{11 \beta K O}$ animals is compared directly, lack of $11 \beta-H S D 1$ function produces a marked right shift in fiber size distribution (i.e., an abundance of larger fibers and scarcity of smaller fibers (Figure 3G)). To summarize the data from muscle weights and histology, suppression of $11 \beta$-HSD1 activity eliminates the atrophic effects of glucocorticoid therapy on skeletal muscle in the context of chronic inflammation.

\subsection{1ß-HSD1 KO Diminishes Activation of Muscle Catabolic Pathways in Response to Therapeutic Glucocorticoid}

Inflammation and glucocorticoids are known to mediate muscle atrophy through induction of overlapping catabolic signaling pathways. To elucidate the mechanism by which $11 \beta-H S D 1$ contributes to muscle wasting in our model of glucocorticoid therapy for chronic inflammation, we examined several regulators of muscle protein metabolism. FoxO1 is a transcription factor and negative regulator of muscle growth [4]. Corticosterone induced FoxO1 mRNA expression in muscle of TNF-tg mice (fold change $=3.16, p<0.05$ ), but this response was diminished in animals with 11 $\beta$-HSD1 deletion (fold change $=2.28, p$-value NS; Figure 4A). Data on phosphorylation of FOXO1, an inactivating modification, mirrors data on total FOXO1 expression. Corticosterone lowered relative phosphorylation/inactivation of FOXO1 in TNF-tg mice $(p<0.001)$, but not in TNF-tg ${ }^{11 \beta K O}$ mice ( $p$-value NS; Figure 4D). Trim63 (also known as MuRF1), an E3 ubiquitin ligase involved in proteolysis, was also upregulated by corticosterone treatment in muscle of TNF-tg mice (fold change $=3.03$, $p<0.01$ ), but not in TNF-tg ${ }^{11 \beta K O}$ mice (fold change $=1.10, p$-value NS; Figure $4 \mathrm{~B}$ ). However, the same pattern was less clear for Fbxo32, a constituent of the catabolic ubiquitin protein ligase complex. mRNA expression of Fbxo32 in muscle was upregulated by corticosterone in both TNF-tg and TNF-tg 11 KO mice (fold changes 4.75, $p<0.01$ and 3.24, $p<0.01$ respectively; Figure 4C). Finally, phosphorylation of ribosomal protein S6, a regulator of mRNA translation and protein synthesis, was not significantly different between TNF-tg and TNF-tg ${ }^{11 \beta K O}$ mice and appeared unaffected by corticosterone treatment in either animal group (Figure 4E,F). To gain further insights, we conducted in vitro experiments using primary muscle cell cultures from WT and $11 \beta \mathrm{KO}$ mice. Expression of myostatin $(M s t n)$, an inhibitory factor for muscle growth, increased on stimulation with the inactive glucocorticoid DHC in wild type muscle cells, but not in $11 \beta \mathrm{KO}$ muscle cells (Figure 4G,H). TNF- $\alpha$ did not induce Mstn. Expression of Fbxo32 increased with both DHC and TNF- $\alpha$ stimulation with additive effects in wild type muscle cells, but the response to DHC was again absent in $11 \beta \mathrm{KO}$ muscle cells (Figure $4 \mathrm{I}, \mathrm{J}$ ). Summing up the observations on regulators of muscle metabolism, glucocorticoid therapy in our model of chronic inflammation potently activates muscle catabolic signaling pathways. Genetic deletion of $11 \beta-H S D 1$ diminishes the glucocorticoid-triggered activation of catabolic signals. 
A

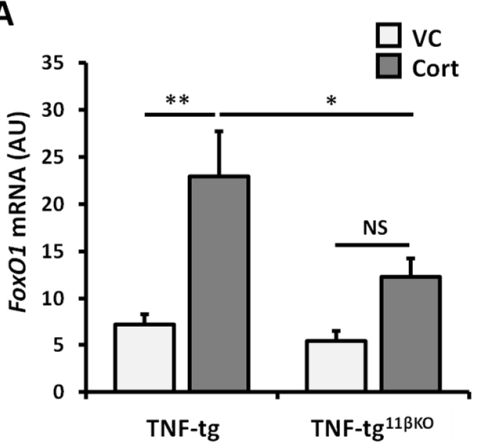

D

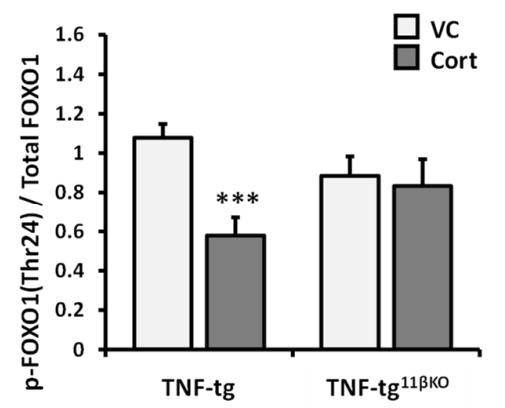

B

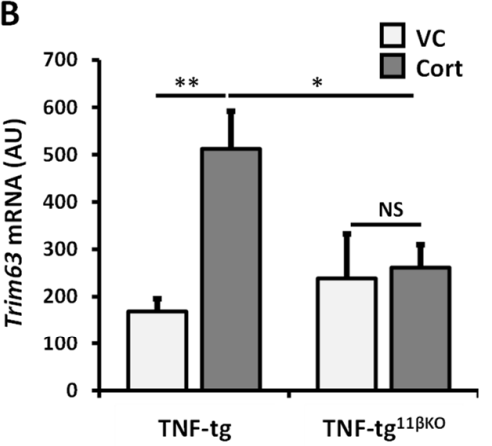

E

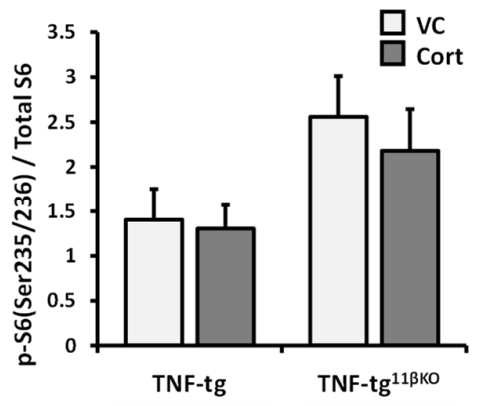

I

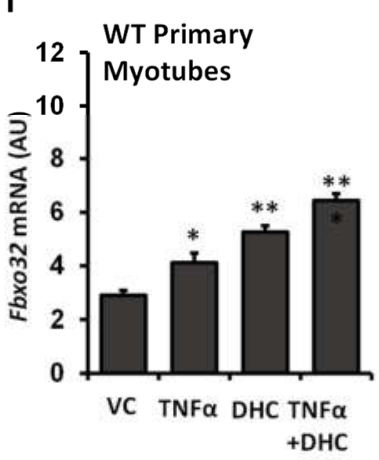

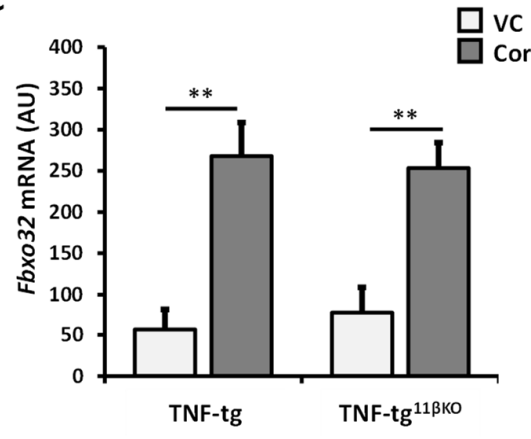

$\mathbf{F}$

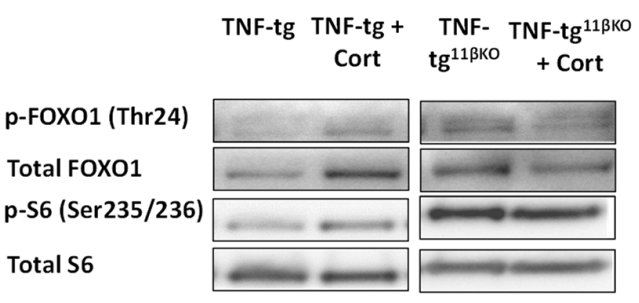

J

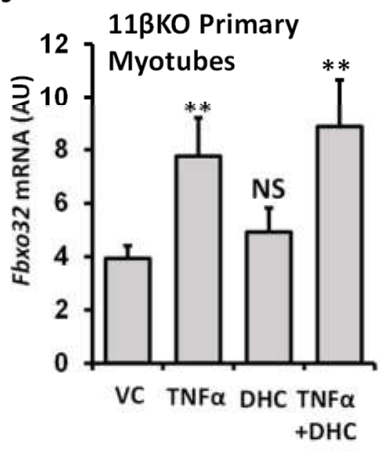

Figure 4. Gene expression (AU) of (A) Foxo1, (B) Trim63, and (C) Fbxo32 determined by RT qPCR in muscle homogenates from TNF-tg, and TNF-tg ${ }^{11 \beta K O}$ animals receiving either vehicle or corticosterone $(100 \mu \mathrm{g} / \mathrm{mL})$ in the drinking water for 3 weeks. (D) The p-FOXO1(Thr24)/Total FOXO1 and (E) p-S6(Ser235/236)/Total S6 ratios and (F) representative western blot staining after loading of $20 \mu \mathrm{g}$ of protein and normalization to Ponceau staining in quadriceps for TNF-tg and TNF$\operatorname{tg}^{11 \beta K O}$ animals receiving either vehicle or corticosterone $(100 \mu \mathrm{g} / \mathrm{mL})$ in the drinking water for 3 weeks. Gene expression $(\mathrm{AU})$ of $(\mathbf{G}, \mathbf{H})$ Mstn and (I,J) Fbxo32 in primary murine muscle cultures from WT and single mutant $11 \beta \mathrm{KO}$ animals treated with recombinant TNF $\alpha$ and/or dehydrocorticosterone (DHC) determined by RT qPCR. Values are expressed as mean $\pm \mathrm{SE}$, $\mathrm{n}=6$ per group for animal experiments and $\mathrm{n}=3$ per group for primary culture. Statistical significance was determined using two-way analysis of variance with Tukey post hoc analysis. ${ }^{*} p<0.05,{ }^{* *} p<0.005,{ }^{* * *} p<0.001$. WT, Wild type; $11 \beta K O, 11 \beta-H S D 1$ genetic deletion; VC, Vehicle Control; Cort, Corticosterone; DHC, Dehydrocorticosterone.

\section{Discussion}

This study reports new knowledge on enhanced glucocorticoid activation in skeletal muscle of patients with rheumatoid arthritis. Furthermore, it provides new insights into the role of $11 \beta$-HSD1 for exogenous glucocorticoid therapy in an inflammatory disease model, building on previous research that examined the role of $11 \beta-\mathrm{HSD} 1$ either for exogenous glucocorticoid excess in non-inflammatory models or endogenous glucocorticoid effects in inflammatory models $[8,13]$. In the therapeutic model of TNF-transgenic mice receiving oral corticosterone as anti-inflammatory treatment, genetic deletion of the glucocorticoid activating enzyme $11 \beta$-HSD1 abolished immunosuppressive responses in muscle. At the same time, 11 $\beta$-HSD1 deletion mitigated the adverse effects of glucocorticoid therapy on 
skeletal muscle, protecting against muscle atrophy and diminishing activation of catabolic signaling pathways.

Examination of human skeletal muscle biopsies corroborates that inflammation upregulates enzymatic activity of $11 \beta-H S D 1$ to activate glucocorticoids locally within muscle. $11 \beta$-HSD1 activity was higher for patients with chronic inflammation from rheumatoid arthritis compared to age-matched patients with osteoarthritis. Furthermore, 11ß-HSD1 activity correlated with systemic and tissue-specific markers of inflammation among patients with rheumatoid arthritis. The confirmation of $11 \beta$-HSD1 upregulation in skeletal muscle of humans with inflammatory disease concords with previous findings. 11 $\beta$-HSD1 activity in human muscle rises following ex vivo stimulation with TNF- $\alpha$ [13], or following a major inflammatory insult like abdominal surgery [17]. Furthermore, 11ß-HSD1 activity by systemic measures or in tissues besides muscle correlates consistently with inflammation in a range of human observational studies [18-21]. Cell culture experiments clarified that inflammatory cytokines like TNF- $\alpha$ or IL1 $\beta$ directly enhance $11 \beta-H S D 1$ expression via the $\mathrm{NFKB}$ signaling pathway $[12,13]$. Altogether, there is strong evidence for upregulation of $11 \beta$-HSD1 activity in skeletal muscle by inflammation.

The inflammatory upregulation of 11ß-HSD1 in skeletal muscle may provide a physiological defense against excessive inflammatory injury, locally amplifying and targeting immunosuppressive actions of endogenous steroids. Deletion of 11 $\beta$-HSD1 accordingly exacerbates myopathy in TNF-tg mice with untreated inflammation [13]. Nevertheless, tissue-specific markers of inflammation as well as muscle atrophy markers remained elevated in our cohort with rheumatoid arthritis compared to osteoarthritis. This was despite elevated 11ß-HSD1 activity in muscle and in the absence of concurrent glucocorticoid therapy. It remains unclear whether catabolic signaling in this setting of human disease is predominantly due to persisting inflammatory injury or due to augmented atrophic action of endogenous steroids. Future studies with detailed phenotyping following anti-inflammatory or $11 \beta$-HSD1 blocking interventions would be needed to address this question.

The significance of $11 \beta$-HSD1 function for the anti-inflammatory efficacy of therapeutic glucocorticoids is demonstrated in the TNF-tg animal model. Deletion of $11 \beta$-HSD1 led to loss of immunosuppressive responses in skeletal muscle that are normally seen with corticosterone treatment. Morgan et al. previously showed that $11 \beta-H S D 1$ function is required for glucocorticoid action on muscle in terms of myopathic effects in a model of exogenous glucocorticoid excess [8]. Our data confirm that 11 $\beta$-HSD1 function is equally important for glucocorticoid action on muscle in terms of immunosuppressive effects in a model of therapeutic glucocorticoid use. These observations in muscle tissue mirror findings from other tissue types. Corticosterone treatment failed to suppress joint inflammation in mouse models of polyarthritis when 11 $\beta$-HSD1 function was absent [16]. Notably, this is true for administration of active glucocorticoids. Corticosterone treatment led to equivalent adrenal atrophy in TNF-tg and TNG-tg ${ }^{11 \beta K O}$ animals, indicating that glucocorticoid-mediated suppression of the HPA axis was preserved. Considering these findings together suggests that $11 \beta-H S D 1$ is critical for sustaining or targeting activity of administered glucocorticoids to exert anti-inflammatory effects.

Genetic deletion of $11 \beta-H S D 1$ protected against muscle wasting in our model of glucocorticoid therapy for inflammatory disease. Results from muscle weights and fiber size distribution were supported by analysis of catabolic signaling pathways. $11 \beta \mathrm{KO}$ diminished activation of FoxO1 and Trim63 (also known as MuRF1) in muscle of TNF-tg mice receiving corticosterone. Fbxo32 was not suppressed in this specific context, suggesting active glucocorticoid administration without signal augmentation by $11 \beta-H S D 1$ was sufficient for this response. The greater glucocorticoid sensitivity of Fbxo32 may reflect synergistic activation with TNF, as observed in our in vitro data, possibly via the transcription factor $C / \operatorname{EBP} \beta[22,23]$.

Glucocorticoid-induced muscle atrophy was prevented despite failure of immunosuppression and higher inflammatory markers in muscle from 11 $\beta$-HSD1-deficient TNF- 


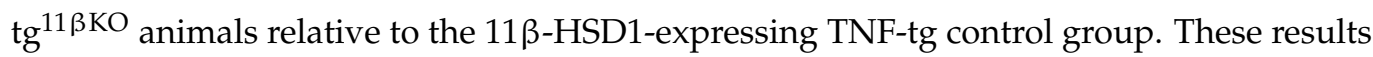
are different from observations from untreated TNF-tg mice. 11ßHSD1 deletion had no effect on muscle phenotype of vehicle-treated TNF-tg mice in this study, or exacerbated muscle wasting in previous reports [13]. Apparent discrepancies in this regard may be attributed to the timepoint of muscle phenotype assessment, which was earlier in the current study to pre-empt treatment-resistant phenotype divergence. Matching our results from glucocorticoid-treated TNF-tg mice, $11 \beta-H S D 1$ deletion also mitigated myopathy in wild-type animals receiving excess exogenous glucocorticoid [8]. Altogether, this supports an interpretation that myopathic effects from glucocorticoid therapy predominated over myopathic effects of inflammation in our model of TNF-tg mice treated with oral corticosterone. Further validation of this concept in human disease is needed. Nevertheless, it matches clinical experiences of muscle wasting as a common adverse effect with glucocorticoid therapy for inflammatory disease [3,24]. In parallel with animal models receiving exogenous glucocorticoids, glucocorticoid doses for immunosuppression in clinical practice are much above physiological equivalents. The principal observations from our study (elevated $11 \beta$-HSD1 activity in muscle in the inflammatory disease rheumatoid arthritis and dependency of adverse glucocorticoid effects on 11 $\beta$-HSD1 function in the animal model) considered together allow the conclusion that inflammatory upregulation of $11 \beta-\mathrm{HSD} 1$ in skeletal muscle may increase patients' susceptibility to glucocorticoid-mediated myopathy. Therefore, there is a strong argument that $11 \beta$-HSD1 activity has a critical contribution to myopathy from glucocorticoid therapy.

Our study highlights a central role of $11 \beta-H S D 1$ activity for action of glucocorticoids on skeletal muscle, in terms of beneficial anti-inflammatory effects as well as harmful myopathic effects. Using primary muscle cell cultures from wild-type and $11 \beta \mathrm{KO}$ mice without transgenic TNF $\alpha$ expression, we showed that skeletal muscle tissue has sufficient capacity for glucocorticoid activation to downregulate cytokines and upregulate catabolic mediators in an auto-/paracrine manner. Even though minor variations between separate primary cultures are possible, this approach allowed most reliable 11 $\beta-H S D 1$ suppression and a clear delineation of response patterns. Inactive DHC, which requires conversion to corticosterone to trigger glucocorticoid responses, induced GILZ, myostatin and Fbxo32 expression and suppressed TNF $\alpha$-stimulated IL6 expression in 11 $\beta$-HSD1 expressing myotubes, but not in myotubes with genetic deletion of $11 \beta$-HSD1. Reduced DHC responses for myostatin and arguably GILZ in the presence of TNF could indicate possible glucocorticoid resistance, a finding that would require further characterization [25].

There remains uncertainty to what extent the observed muscle phenotype in vivo is caused by $11 \beta-H S D 1-m e d i a t e d$ glucocorticoid activation directly within muscles, as opposed to $11 \beta$-HSD1 activity elsewhere in the body. Previous studies suggest that $11 \beta-$ HSD1 activity in myeloid cells is important for immunosuppression by glucocorticoids in vivo [16], while 11 $\beta$-HSD1 activity in liver appeared irrelevant for myopathic effects [8]. Variable activity of $11 \beta$-HSD1 in different tissue types may determine the balance of beneficial immunosuppressive versus harmful metabolic effects with glucocorticoid therapy. Further research with tissue-targeted glucocorticoid delivery or 11ß-HSD1 suppression is needed to clarify this concept and advance the safety of glucocorticoid-based therapies.

Clinical data on the potential benefits of $11 \beta-H S D 1$ inhibition on muscle metabolism is emerging. Observational studies have reported a correlation of 11 $\beta$-HSD1 expression in muscle with total lean mass and muscle strength in healthy elderly $[26,27]$. Furthermore, a clinical trial found that the 11 $\beta-H S D 1$ inhibitor AZD4017 increased total lean mass in young overweight women [11]. Finally, the TICSI trial is of particular interest in relation to the findings reported here (ClinicalTrials.gov (accessed on 12 July 2021) ID: NCT03111810). It aims to determine whether co-administration of an 11 $\beta-H S D 1$ inhibitor can limit the metabolic side effects of prednisolone, with results expected to report in the near future. However, safety data will be needed to confirm that 11 $\beta$-HSD1 inhibitors do not exacerbate inflammatory pathology before using them in patients requiring immunosuppressive therapy. Given that 11 $\beta$-HSD1 mediates both immunosuppressive and metabolic effects 
of glucocorticoids, tissue-targeted strategies may hold greater promise than systemic $11 \beta$ HSD1 inhibition.

\section{Materials and Methods}

All biochemical reagents used are from Sigma, Dorset, United Kingdom, unless stated otherwise.

\subsection{Human Skeletal Muscle Biopsies}

Adult patients with hip osteoarthritis (OA) or rheumatoid arthritis (RA) consented to collection of quadriceps muscle biopsies (150-200 mg) during elective joint replacement surgery, following ethical approval (REC reference 14/ES/1044 \& NRES 16/SS/0172). Current glucocorticoid therapy was an exclusion criterion. Fresh muscle tissue was used either immediately for enzymatic activity analysis, or snap-frozen in liquid nitrogen for later real-time PCR analysis.

\subsection{Animal Models}

Transgenic mice with chronic systemic overexpression of human TNF- $\alpha$ (TNF-tg mice) were used as a model for chronic inflammation and polyarthritis. TNF-tg animals were provided by Professor George Kollias (Biomedical Sciences Research Center 'Alexander Fleming', Athens, Greece). This model, first described by Keffer et al. [28], relies on replacement of the $3^{\prime}$-untranslated region of the human TNF $\alpha$ gene with the $3^{\prime}$-untranslated region of the $\beta$-globin gene, which greatly increases transcriptional efficiency, stability and expression. Human TNF $\alpha$ has homology with murine TNF $\alpha$ and effectively binds murine TNF-R1 receptors, but not murine TNF-R2 receptors, resulting in less severe inflammatory manifestations than chronic overexpression of murine TNF $\alpha[29,30]$. Transgene expression affects multiple tissues (joints, brain, kidney, spleen, thymus) with confirmed expression in murine skeletal muscle tissue $[13,28]$. We have previously demonstrated high levels of human TNF $\alpha$ transgene expression and equivalent levels of native murine TNF $\alpha$ expression in skeletal muscle of TNF-tg mice compared to wild-type mice [13]. The characteristic phenotype of these animals involves progressive polyarthritis from 6 weeks of age. The inflammatory and musculoskeletal phenotype of these TNF-tg mice has previously been described $[13,15,16,31]$. TNF-tg mice were crossed with 11 $\beta$-HSD1 global KO mice $(11 \beta K O)$ as previously described to generate TNF-tg ${ }^{11 \beta K O}$ animals [16]. All animals were maintained on C57BL/ 6 background and littermates with intact 11 $\beta$-HSD1 gene served as respective controls. Preserved human TNF $\alpha$ transgene expression in skeletal muscle tissue of double mutant mice has previously been validated [13] and was confirmed for this study (Supplementary Figure S1).

Male mice were housed in standard conditions with ad lib access to standard chow and water. Animals were scored twice weekly for clinical parameters of inflammation using a validated template $[13,31]$ from 28 days of age until the end of the experiment. Treatment with glucocorticoids or vehicle started from 32 days of age, coinciding with onset of measurable polyarthritis, and continued for 3 weeks. Drinking water was supplemented with either corticosterone $(100 \mu \mathrm{g} / \mathrm{mL}, 0.66 \%$ ethanol), or vehicle $(0.66 \%$ ethanol $)$, with an average consumption of $1.25 \mathrm{mg}$ per day. Mice were sacrificed at the end of 3 weeks treatment. Adrenal glands, tibialis anterior (TA) and quadriceps muscle were dissected, weighed and weights normalized to total body weights. Muscles were snap frozen in liquid nitrogen and stored at $-80^{\circ} \mathrm{C}$ for later biochemical analysis. Experiments complied with the Animal (Scientific Procedures) Act 1986 and received approval from the Birmingham Ethical Review Subcommittee (project license P51102987).

\subsection{1ß-HSD1 Enzymatic Activity Assay}

Confluent cells or fresh tissues were incubated in medium containing $100 \mathrm{nmol} / \mathrm{L}$ cortisone (for human samples) or $100 \mathrm{nmol} / \mathrm{L}$ DHC (for rodent samples) along with tracer amounts of tritiated cortisone or tritiated DHC (Perkin Elmer, Beaconsfield, UK). 
Steroids were extracted in dichloromethane and separated by thin-layer chromatography with ethanol/chloroform (8:92) as the mobile phase. Thin-layer chromatography plates were analyzed with a Bioscan imager (Bioscan, Washington, DC, USA), and the fractional conversion of steroids was calculated. The protein concentration was determined with the Bio-Rad Protein assay using the Bradford method (Bio-Rad, Hercules, CA, USA). Experiments were performed in triplicate, and enzymatic activity is reported as pmol product per mg protein per hour.

\subsection{Primary Murine Muscle Cell Culture}

Murine TA muscles were used to generate primary cultures of differentiated myotubes as previously described [32,33]. TA muscles were removed from WT and $11 \beta \mathrm{KO}$ mice at 9 weeks and digested in type 1 collagenase at $37^{\circ} \mathrm{C}$ for $2 \mathrm{~h}$, before isolating individual fibers. Fibers were plated in satellite media (DMEM High Glucose, 30\% FBS, 10\% HS, $1 \%$ Chick Embryo Extract, $10 \mathrm{ng} / \mathrm{mL}$ basic fibroblast growth factor) and grown in Matrigel ${ }^{\mathrm{TM}}$-coated plates (Corning Life Sciences, Flintshire, UK). Satellite cells migrating from muscle fibers were removed and cultured in proliferation medium (DMEM High Glucose, 10\% HS, 0.5\% Chick Embryo Extract) until confluent. Primary myoblasts were then grown in differentiation medium (DMEM High Glucose, $2 \%$ HS) for five days until syncytialized myotubes formed. To investigate effects of inflammation and glucocorticoids, differentiated myotubes were incubated in media with added TNF- $\alpha(10 \mathrm{ng} / \mathrm{mL})$ and/or dehydrocorticosterone $(1 \mu \mathrm{mol} / \mathrm{L})$ for $24 \mathrm{~h}$.

\subsection{RNA Isolation and Analysis of Gene Expression}

RNA was extracted by mechanical suspension and lysis of muscle in TRIzol ${ }^{\mathrm{TM}}$ reagent (Thermo Fisher Scientific, Loughborough, UK). Phase separation and RNA precipitation was performed with the addition of chloroform and 2-propanol. RNA precipitates were reconstituted in RNase-free water and stored at $-80^{\circ} \mathrm{C}$. cDNA was generated by reverse transcription in accordance with the manufacturer's protocol (Multiscribe ${ }^{\mathrm{TM}}$, Thermo Fisher Scientific, Loughborough, UK). Expression of specific genes was assessed by real-time PCR using TaqMan ${ }^{\circledR}$ Gene Expression Assays (Thermo Fisher Scientific, Loughborough, UK) on an ABI7500 system (Applied Biosystems, Warrington, UK). Final reactions contained 2X TaqMan PCR Mastermix (Thermo Fisher Scientific, Loughborough, UK), $200 \mathrm{nmol}$ TaqMan probe and 25-50 ng cDNA. The abundance of specific mRNAs in a sample was normalized to the housekeeper gene GAPDH by calculating $\Delta \mathrm{Ct}$ values (Ct target $-\mathrm{Ct}$ GAPDH). For graphical illustrations, standardized expression values were transformed with the formula $\left(2^{-\Delta \mathrm{Ct}}\right) \times 1000$. For describing changes between experimental and control groups, the difference of $\Delta \mathrm{Ct}$ values as calculated as $\Delta \Delta \mathrm{Ct}=\Delta \mathrm{Ct}$ [experimental group] $-\Delta \mathrm{Ct}$ [control group] and reported as fold change $=2^{\Delta \Delta \mathrm{Ct}}$.

\subsection{Histological Analysis of Muscle}

Murine quadriceps muscles were embedded in paraffin and cut to $10 \mu \mathrm{m}$ sections for histology. Samples were stained with hematoxylin and eosin prior to quantitative analysis of fiber size distribution using Image J software [34]. Measurements were taken in three $200 \mu \mathrm{m}^{2}$ regions of the vastus medialis for six mice per group.

\subsection{Western Blots}

Protein content of quadriceps muscles was homogenized in an ice-cold lysis buffer (50 $\mathrm{mM}$ Tris, $1 \mathrm{mM}$ EDTA, $10 \mathrm{mM}$ Na-B-Glycerophosphate, $5 \mathrm{mM}$ Na-Pyrophosphate, $1 \mathrm{mM}$ Benzamidine, $250 \mathrm{mM}$ Sucrose, $50 \mathrm{mM} \mathrm{NaF}, 0.1 \%$-Mercaptoethanol, $1 \mathrm{mM} \mathrm{Na} 2 \mathrm{VO}$, $1 \%$ Triton $X$ and Protease Inhibitor Cocktail (Merck Life Science, Dorset, UK)). Proteins were denatured in Laemmli buffer at $95{ }^{\circ} \mathrm{C}$ for $5 \mathrm{~min} .20 \mu \mathrm{g}$ of proteins were resolved in Tris-glycine SDS-PAGE gels and transferred onto polyvinylidene difluoride membranes. After blocking, membranes were probed with the primary antibody overnight at $4{ }^{\circ} \mathrm{C}$. All primary antibodies were obtained from Cell Signaling Technology, Inc. and diluted 
at 1:1000 in TBS-Tween plus 5\% BSA or skimmed milk (p-FOXO1 \#9464, FOXO1 \#2880, p-S6 Ribosomal Protein (Ser235/236) \#4856, S6 Ribosomal Protein \#2217). Signal detection used horseradish peroxidase-conjugated secondary antibodies and ECL substrate. The membrane was stained with Ponceau S solution $(0.2 \%$ Ponceau $S$ in $1 \%$ acetic acid; SigmaAldrich Chemie) to control for protein loading.

\subsection{Statistical Analysis}

Data was analyzed by unpaired $t$-test, one way and two-way ANOVA with Tukey post-hoc analysis or Pearson correlation analysis, or non-parametric equivalent tests as appropriate using GraphPad Prism [35]. Aggregate data are reported as mean \pm standard error, unless otherwise specified. Statistical significance was defined as $p$-value $<0.05$ $\left({ }^{*} p<0.05 ;{ }^{* *} p<0.01 ;{ }^{* * *} p<0.001\right.$; no asterisk or NS $\left.p>0.05\right)$.

Supplementary Materials: The following are available online at https:/ /www.mdpi.com/article/10 .3390/ijms22157828/s1.

Author Contributions: Conceptualization, R.S.H., R.L., M.S.C., K.R. and G.G.L.; investigation, J.M.W., C.G.F. with support from M.S.S., A.P.S., Y.-C.L., S.W.J., A.F. and R.S.H.; writing—original draft preparation, M.S.S.; writing—review and editing, J.M.W., M.S.S., M.S.C., K.R., R.L. and R.S.H.; supervision, R.S.H., R.L., M.S.C., K.R. and G.G.L. All authors have read and agreed to the published version of the manuscript.

Funding: This research was funded by the Arthritis Research UK grants number 19859 \& 20843. MSS is funded by MRC Clinical Research Training Fellowship (MR/T008172/1). KR and AF are supported by the NIHR Birmingham Biomedical Research Centre.

Institutional Review Board Statement: The study was conducted according to the guidelines of the Declaration of Helsinki. Research involving human participants was approved by the East of Scotland Research Ethics Service REC 2 (reference 14/ES/1044, date of approval 12 August 2014) and by the South East Scotland Research Ethics Committee 1 (reference 16/SS/0172, date of approval 31 October 2016). Research involving animals complied with the Animal (Scientific Procedures) Act 1986 and received approval from the Birmingham Ethical Review Subcommittee (project license P51102987).

Informed Consent Statement: Informed consent was obtained from all subjects involved in the study.

Data Availability Statement: Data and materials within this manuscript can be made available upon reasonable request to the corresponding author.

Acknowledgments: We would like to thank George Kollias (Biomedical Sciences Research Center 'Alexander Fleming', Athens, Greece) for providing the hTNFtg mice, the Biomedical Services Unit (University of Birmingham) for supporting animal experiments and the Department of Musculoskeletal Pathology (Robert Aitken Institute, University of Birmingham) for embedding and cutting tissue for histology. We would also like to acknowledge the Research into Inflammatory Arthritis Centre Versus Arthritis and the MRC Arthritis Research UK Centre for Musculoskeletal Ageing Research in supporting this work.

Conflicts of Interest: The authors declare no conflict of interest. 


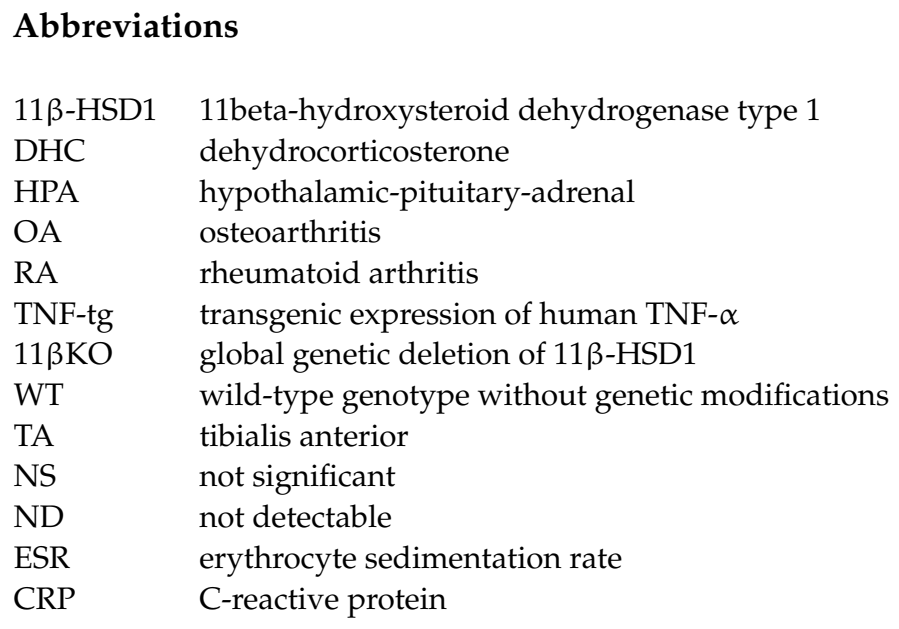

\section{References}

1. Coutinho, A.E.; Chapman, K.E. The anti-inflammatory and immunosuppressive effects of glucocorticoids, recent developments and mechanistic insights. Mol. Cell. Endocrinol. 2011, 335, 2-13. [CrossRef]

2. Rhen, T.; Cidlowski, J.A. Antiinflammatory action of glucocorticoids-New mechanisms for old drugs. N. Engl. J. Med. 2005, 353, 1711-1723. [CrossRef] [PubMed]

3. Oray, M.; Abu Samra, K.; Ebrahimiadib, N.; Meese, H.; Foster, C.S. Long-term side effects of glucocorticoids. Expert Opin. Drug Saf. 2016, 15, 457-465. [CrossRef]

4. Schakman, O.; Kalista, S.; Barbé, C.; Loumaye, A.; Thissen, J.P. Glucocorticoid-induced skeletal muscle atrophy. Int. J. Biochem. Cell Biol. 2013, 45, 2163-2172. [CrossRef]

5. Beaudart, C.; Zaaria, M.; Pasleau, F.; Reginster, J.Y.; Bruyère, O. Health Outcomes of Sarcopenia: A Systematic Review and Meta-Analysis. PLoS ONE 2017, 12, e0169548. [CrossRef]

6. Gathercole, L.L.; Lavery, G.G.; Morgan, S.A.; Cooper, M.S.; Sinclair, A.J.; Tomlinson, J.W.; Stewart, P.M. 11 $\beta$-Hydroxysteroid dehydrogenase 1: Translational and therapeutic aspects. Endocr. Rev. 2013, 34, 525-555. [CrossRef] [PubMed]

7. Morgan, S.A.; Hassan-Smith, Z.K.; Doig, C.L.; Sherlock, M.; Stewart, P.M.; Lavery, G.G. Glucocorticoids and 11 $\beta$-HSD1 are major regulators of intramyocellular protein metabolism. J. Endocrinol. 2016, 229, 277-286. [CrossRef] [PubMed]

8. Morgan, S.A.; McCabe, E.L.; Gathercole, L.L.; Hassan-Smith, Z.K.; Larner, D.P.; Bujalska, I.J.; Stewart, P.M.; Tomlinson, J.W.; Lavery, G.G. 11ß-HSD1 is the major regulator of the tissue-specific effects of circulating glucocorticoid excess. Proc. Natl. Acad. Sci. USA 2014, 111, E2482-E2491. [CrossRef]

9. $\quad$ Feig, P.U.; Shah, S.; Hermanowski-Vosatka, A.; Plotkin, D.; Springer, M.S.; Donahue, S.; Thach, C.; Klein, E.J.; Lai, E.; Kaufman, K.D. Effects of an 11beta-hydroxysteroid dehydrogenase type 1 inhibitor, MK-0916, in patients with type 2 diabetes mellitus and metabolic syndrome. Diabetes Obes. Metab. 2011, 13, 498-504. [CrossRef] [PubMed]

10. Stefan, N.; Ramsauer, M.; Jordan, P.; Nowotny, B.; Kantartzis, K.; Machann, J.; Hwang, J.H.; Nowotny, P.; Kahl, S.; Harreiter, J.; et al. Inhibition of 11beta-HSD1 with RO5093151 for non-alcoholic fatty liver disease: A multicentre, randomised, double-blind, placebo-controlled trial. Lancet Diabetes Endocrinol. 2014, 2, 406-416. [CrossRef]

11. Hardy, R.S.; Botfield, H.; Markey, K.; Mitchell, J.L.; Alimajstorovic, Z.; Westgate, C.S.J.; Sagmeister, M.; Fairclough, R.J.; Ottridge, R.S.; Yiangou, A.; et al. 11ßHSD1 Inhibition with AZD4017 Improves Lipid Profiles and Lean Muscle Mass in Idiopathic Intracranial Hypertension. J. Clin. Endocrinol. Metab. 2021, 106, 174-187. [CrossRef]

12. Ahasan, M.M.; Hardy, R.; Jones, C.; Kaur, K.; Nanus, D.; Juarez, M.; Morgan, S.A.; Hassan-Smith, Z.; Benezech, C.; Caamano, J.H.; et al. Inflammatory regulation of glucocorticoid metabolism in mesenchymal stromal cells. Arthritis Rheum. 2012, 64, 2404-2413. [CrossRef]

13. Hardy, R.S.; Doig, C.L.; Hussain, Z.; O'Leary, M.; Morgan, S.A.; Pearson, M.J.; Naylor, A.; Jones, S.W.; Filer, A.; Stewart, P.M.; et al. $11 \beta$-Hydroxysteroid dehydrogenase type 1 within muscle protects against the adverse effects of local inflammation. J. Pathol. 2016, 240, 472-483. [CrossRef]

14. Webster, J.M.; Kempen, L.; Hardy, R.S.; Langen, R.C.J. Inflammation and Skeletal Muscle Wasting During Cachexia. Front. Physiol. 2020, 11, 597675. [CrossRef] [PubMed]

15. Fenton, C.G.; Webster, J.M.; Martin, C.S.; Fareed, S.; Wehmeyer, C.; Mackie, H.; Jones, R.; Seabright, A.P.; Lewis, J.W.; Lai, Y.C.; et al. Therapeutic glucocorticoids prevent bone loss but drive muscle wasting when administered in chronic polyarthritis. Arthritis Res. Ther. 2019, 21, 182. [CrossRef]

16. Fenton, C.; Martin, C.; Jones, R.; Croft, A.; Campos, J.; Naylor, A.J.; Taylor, A.E.; Chimen, M.; Cooper, M.; Lavery, G.G.; et al. Local steroid activation is a critical mediator of the anti-inflammatory actions of therapeutic glucocorticoids. Ann. Rheum. Dis. 2021, 80, 250-260. [CrossRef]

17. Jang, C.; Obeyesekere, V.R.; Alford, F.P.; Inder, W.J. Skeletal muscle $11 \beta$ hydroxysteroid dehydrogenase type 1 activity is upregulated following elective abdominal surgery. Eur. J. Endocrinol. 2009, 160, 249-255. [CrossRef] 
18. Hardy, R.; Rabbitt, E.H.; Filer, A.; Emery, P.; Hewison, M.; Stewart, P.M.; Gittoes, N.J.; Buckley, C.D.; Raza, K.; Cooper, M.S. Local and systemic glucocorticoid metabolism in inflammatory arthritis. Ann. Rheum. Dis. 2007, 67, 1204-1210. [CrossRef]

19. Nanus, D.E.; Filer, A.D.; Yeo, L.; Scheel-Toellner, D.; Hardy, R.; Lavery, G.G.; Stewart, P.M.; Buckley, C.D.; Tomlinson, J.W.; Cooper, M.S.; et al. Differential glucocorticoid metabolism in patients with persistent versus resolving inflammatory arthritis. Arthritis Res. Ther. 2015, 17, 121. [CrossRef]

20. Sagmeister, M.S.; Taylor, A.E.; Fenton, A.; Wall, N.A.; Chanouzas, D.; Nightingale, P.G.; Ferro, C.J.; Arlt, W.; Cockwell, P.; Hardy, R.S.; et al. Glucocorticoid activation by $11 \beta$-hydroxysteroid dehydrogenase enzymes in relation to inflammation and glycaemic control in chronic kidney disease: A cross-sectional study. Clin. Endocrinol. 2019, 90, 241-249. [CrossRef]

21. Stegk, J.P.; Ebert, B.; Martin, H.J.; Maser, E. Expression profiles of human 11beta-hydroxysteroid dehydrogenases type 1 and type 2 in inflammatory bowel diseases. Mol. Cell. Endocrinol. 2009, 301, 104-108. [CrossRef]

22. Penner, G.; Gang, G.; Sun, X.; Wray, C.; Hasselgren, P.O. C/EBP DNA-binding activity is upregulated by a glucocorticoiddependent mechanism in septic muscle. Am. J. Physiol. Regul. Integr. Comp. Physiol. 2002, 282, R439-R444. [CrossRef]

23. Zhang, G.; Jin, B.; Li, Y.-P. C/EBP $\beta$ mediates tumour-induced ubiquitin ligase atrogin1/MAFbx upregulation and muscle wasting. EMBO J. 2011, 30, 4323-4335. [CrossRef] [PubMed]

24. Yamada, Y.; Tada, M.; Mandai, K.; Hidaka, N.; Inui, K.; Nakamura, H. Glucocorticoid use is an independent risk factor for developing sarcopenia in patients with rheumatoid arthritis: From the CHIKARA study. Clin. Rheumatol. 2020, 39, $1757-1764$. [CrossRef] [PubMed]

25. Dendoncker, K.; Timmermans, S.; Vandewalle, J.; Eggermont, M.; Lempiäinen, J.; Paakinaho, V.; Van Hamme, E.; Dewaele, S.; Vandevyver, S.; Ballegeer, M.; et al. TNF- $\alpha$ inhibits glucocorticoid receptor-induced gene expression by reshaping the GR nuclear cofactor profile. Proc. Natl. Acad. Sci. USA 2019, 116, 12942-12951. [CrossRef] [PubMed]

26. Hassan-Smith, Z.K.; Morgan, S.A.; Sherlock, M.; Hughes, B.; Taylor, A.E.; Lavery, G.G.; Tomlinson, J.W.; Stewart, P.M. Gender-Specific Differences in Skeletal Muscle 11ß-HSD1 Expression Across Healthy Aging. J. Clin. Endocrinol. Metab. 2015, 100, 2673-2681. [CrossRef]

27. Kilgour, A.H.M.; Gallagher, I.J.; Maclullich, A.M.J.; Andrew, R.; Gray, C.D.; Hyde, P.; Wackerhage, H.; Husi, H.; Ross, J.A.; Starr, J.M.; et al. Increased Skeletal Muscle 11ßHSD1 mRNA Is Associated with Lower Muscle Strength in Ageing. PLoS ONE 2013, 8, e84057. [CrossRef]

28. Keffer, J.; Probert, L.; Cazlaris, H.; Georgopoulos, S.; Kaslaris, E.; Kioussis, D.; Kollias, G. Transgenic mice expressing human tumour necrosis factor: A predictive genetic model of arthritis. EMBO J. 1991, 10, 4025-4031. [CrossRef]

29. Lewis, M.; Tartaglia, L.A.; Lee, A.; Bennett, G.L.; Rice, G.C.; Wong, G.H.; Chen, E.Y.; Goeddel, D.V. Cloning and expression of cDNAs for two distinct murine tumor necrosis factor receptors demonstrate one receptor is species specific. Proc. Natl. Acad. Sci. USA 1991, 88, 2830-2834. [CrossRef] [PubMed]

30. Kontoyiannis, D.; Pasparakis, M.; Pizarro, T.T.; Cominelli, F.; Kollias, G. Impaired On/Off Regulation of TNF Biosynthesis in Mice Lacking TNF AU-Rich Elements. Immunity 1999, 10, 387-398. [CrossRef]

31. Naylor, A.J.; Desanti, G.; Saghir, A.N.; Hardy, R.S. TNFalpha depleting therapy improves fertility and animal welfare in TNFalpha-driven transgenic models of polyarthritis when administered in their routine breeding. Lab. Anim. 2018, 52, 59-68. [CrossRef]

32. Rosenblatt, J.D.; Lunt, A.I.; Parry, D.J.; Partridge, T.A. Culturing satellite cells from living single muscle fiber explants. In Vitro Cell. Dev. Biol. Anim. 1995, 31, 773-779. [CrossRef] [PubMed]

33. O'Leary, M.F.; Wallace, G.R.; Bennett, A.J.; Tsintzas, K.; Jones, S.W. IL-15 promotes human myogenesis and mitigates the detrimental effects of TNFalpha on myotube development. Sci. Rep. 2017, 7, 12997. [CrossRef]

34. Rasband, W.S. ImageJ; National Institutes of Health: Bethesda, MD, USA, 2018. Available online: https://imagej.nih.gov/ij/ (accessed on 12 July 2021).

35. Mutulsky, H. GraphPad Prism; GraphPad Software: San Diego, CA, USA, 2021; Available online: www.graphpad.com (accessed on 12 July 2021). 